\title{
Combustion of Dual Fuel Type Natural Gas/Liquid Diesel Fuel in Compression Ignition Engine
}

\author{
Miqdam Tariq Chaichan \\ Mechanical Engineering Dep. - University of Technology- Baghdad-Iraq
}

\begin{abstract}
The purpose of this investigation is studying the characteristics of single cylinder diesel engine Ricardo E6 performance and emissions run with natural gas and diesel in dual fuel mode. In dual fuel operation, the major part of the energy released resulted from the combustion of the gaseous fuel. In the other hand, the small amount of diesel fuel provides an ignition source. Equivalence ratios, engine speed, and injection timing effects on the brake specific fuel consumption and engine exhaust emissions were examined for natural gas-diesel fuel operation and compared with neat diesel operation. The results demonstrate that, the dual fuel engine reduced $\mathrm{NO}_{X}$ emissions clearly over a wide range of operating conditions. However, under lean equivalence ratios and low loads, the exhausted CO and HC emissions were high. Also, a higher BSFC resulted when compared to those of the diesel engine.
\end{abstract}

Keywords: $\mathrm{CO}$, dual-fuel, emissions, engine performance, $N G, N O x, U B H C$

\section{Introduction}

Environmental hazards and the rising price of oil have stimulated fuel diversification and led to the creation of alternative fuel sources for conventional internal combustion engines. Adding gaseous fuel as partial supplement to liquid fuel in compression ignition engines is an example. Such operation, known as "dual fuel", is an attractive and flexible way for utilizing various types of gaseous fuels, including natural gas. The dual fuel mode concept include the utilization of gaseous fuel by mixing it with the intake air first. The ignition of this premixed lean charge is achieved by injecting a small quantity of pilot diesel fuel, near top dead centre at the compression stroke. These pilot fuel droplets will auto-ignite to provide an ignition source for the surrounding gaseous fuel-air mixture [1 \& 2].

Early in the development of the diesel engine, the concept of operating on gaseous fuels with pilot oil ignition was recognized. Dr. Rudolf Diesel was granted a patent in 1898 for his method consisting of the injection of a liquid fuel to start the combustion of the working mixture of a gaseous fuel and air in the engine cylinder. However, the dual fuel commercial development only goes back to the late 1930's when a stationary dual fuel engine fuelled with town gas was produced and operated in England [3].

Much research effort has been expended so far towards providing effective measures to the further improvement of dual fuel operation of compression ignition engines [4, $5 \& 6]$. The effects of the initial charge temperature variation, oxygen and diluents concentrations, and pilot liquid fuel quantity and injection characteristics on the length of the ignition delay period of the pilot were investigated by [7 \& 8]. Their studies indicated that the followings are the major factors that control the extent of the ignition delay period and cyclic variations, and exhaust emissions of dual fuel engines in general and at light load in particular:

- Changes in the mean charge temperature and pressure resulted from the variations in its physical properties at the end of the compression stroke.

- Pre-ignition energy release due to chemical reactions.

- External heat transfer and effects of residual gas mixing.

Many investigations studied the combustion characteristics and exhausted emissions in dual gas- diesel engines. Ref. [9] indicated in his study on a direct injection, naturally aspirated CFR engine that the amount of gas reacted depended on the gas-air mixture strength and the diesel quantity employed. He suggested on these bases that there is a lower limit of mixture flammability. They also found that at light load, a part of the gaseous fuel was left to pass unburnt through the engine cylinder, probably due to the poor flame propagation. The results are poor fuel utilization, reduced power output, and lower efficiency. The operational problems due to the poor utilization of gaseous fuel at low loads have been widely recognized and have drawn considerable attention in dual fuel research over the years. The findings of $[10,11 \& 12]$ confirmed that with very lean gaseous fuel-air ratios. The flames initiated from the multitude of the ignition centers of the liquid diesel pilot spray failed to propagate throughout the whole combustion chamber, leaving various amounts of the gaseous fuel-air charge unconverted.

The work of Pereira [13] used a single cylinder direct injection engine to study of methane fuelled dual fuel engine. The tests were based on measurements of exhaust emissions over an extended range of pilot 
injection timings, injection pressures, and intake temperatures. He reported that the concentration of $\mathrm{CO}$ and unburnt hydrocarbons peaked around mixture strength of an equivalence ratio of 0.4 to 0.5 . Any increase or decrease in the gaseous fuel concentration could reduce the presence of $\mathrm{CO}$ and unreacted $\mathrm{HC}$, in the exhaust gas.

Studies by References [11 \& 14] established that the ignition and combustion processes depended not only on the injection and ignition characteristics of the diesel pilot, but also depended strongly on the type and concentration of the gaseous fuel employed. Saidur [15] used NG fumigation in a single cylinder, direct injection diesel engine. He replaced up to $80 \%$ (on an energy basis) of the liquid fuel by gas. The tests were conducted mainly to reduce particulate emissions. He observed colossal associated increases in unburnt hydrocarbons (HC) and $\mathrm{CO}$ emissions.

The aim of the recent study was to investigate the possibility of operating diesel engine on dual fuel mode and the effect of some engine variables on the performance and the emitted emissions experimentally.

\section{Experimental Setup}

The engine used in the recent study is a single cylinder, variable compression ratio, indirect injection diesel engine Ricardo E6. The engine geometry and operating parameters are listed in Table 1. The engine cylinder head is a compression swirl combustion chamber type Ricardo Comet Mk V. This system consists of two sections: The first one is swirl chamber in the head with a top half of spherical form, and the lower half is a truncated cone which communicates with the cylinder by means of a narrow passage or throat. The second part consists of special cavities cut into the crown of the piston. The engine can run on 100\% diesel fuel or dual fuel. The engine was converted to run on NG-diesel dual fuel by introducing NG in the suction manifold by means of a gas adapter. The gas regulator was adjusted at a pressure slightly higher than atmospheric pressure.

Table 1 Ricardo E6 engine geometry and operating parameters

\begin{tabular}{|r|r|}
\hline I. VAluE & II. DESCRIPTION \\
\hline Displaced Volume & $504 \mathrm{~cm}^{3}$ \\
\hline Bore & $76.2 \mathrm{~mm}$ \\
\hline Stroke & $111.1 \mathrm{~mm}$ \\
\hline Exhaust Valve Open & $43^{\circ} \mathrm{BBDC}$ (at 5 mm lift) \\
\hline Exhaust Valve Close & $6^{\circ} \mathrm{ATDC}$ (at 5 mm lift) \\
\hline Inlet Valve Open & $8^{\circ} \mathrm{BTDC}$ (at 5 mm lift) \\
\hline Inlet Valve Close & $36^{\circ} \mathrm{ABDC}$ (at 5 mm lift) \\
\hline Speed & III. $1500 \mathrm{RPM}(25 \mathrm{RPS})$ \\
\hline
\end{tabular}

Fig. 1 reveals a schematic diagram of the engine test rig. An electrical dynamometer was used to load the engine. The engine equipped for all operating parameters measurements and combustion noise data. Two tanks were used to measure diesel flow rate, the main tank (9 liters) and secondary tank (1 liter). The system furnished with a set of valves to control fuel flow and a fuel flow measurement device. The NG flow rate measured by means of an orifice meter connected to an inclined manometer.

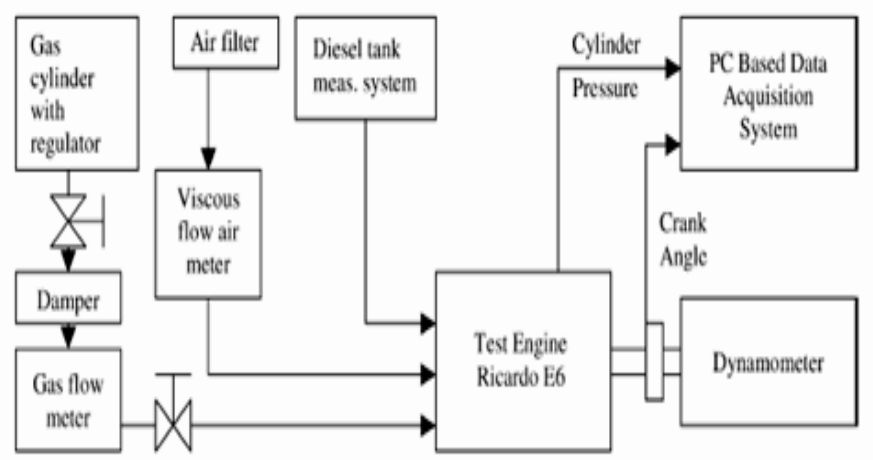

Fig. 1: the engine test rig schematic diagram

The engine speed, load, and diesel/NG replacement ratio was varied to determine their influences on the performance and emission during engine operation. The measurements ranges were: load (bmep) from 0 to 12.7 bars, speed from 1000 to $2100 \mathrm{rpm}$, NG substitution ratio was 30 and 60 percent (from diesel fuel volume). Iraqi diesel fuel (with cetane number= 49) was used in the tests. Iraqi NG (NG used produced from Iraqi Northern Gas Company was used in dual fuel mode operation. This gas consisted of $84.23 \%$ methane, $13.21 \%$ ethane, $2.15 \%$ propane, $0.15 \%$ iso-butane, $0.17 \% \mathrm{n}$. butane and $0.03 \%$ pentane. 
The engine was left to run several minutes until it reaches steady state, so the engine oil temperature reached $60^{\circ} \mathrm{C} \pm 5$, and cooling water temperature is at $70^{\circ} \mathrm{C} \pm 5$. The engine design and operating parameters varied at the following levels:

1. The engine load was chosen as the maximum load for each studied case.

2. The injection timing was varied from 20 to $50^{\circ} \mathrm{BTDC}$ in steps of $5^{\circ} \mathrm{CA}$.

3. The engine speed was varied from 1000 to $2100 \mathrm{rpm}$.

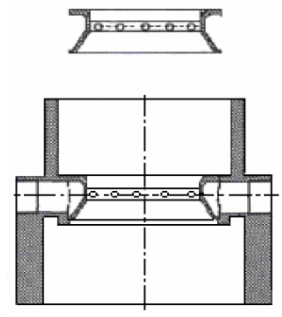

Fig.2: The cross-sectional drawing of the mixer

In a dual fuel mode operation case, the engine was run with NG-air mixture. The mixture had 30 and $60 \%$ NG on a volume basis was ignited by the pilot diesel. The injection system was regulated to supply the minimum quantity of diesel during the dual operation to achieve a smooth operation. Tests were conducted with neat diesel as a basis for comparison. Engine was made to run on no load condition, and its speed was regulated to $1500 \mathrm{rpm} \pm 20 \mathrm{rpm}$. After the engine had reached uniform speed, then it was gradually loaded. Maximum load levels were chosen to evaluate the effect of other variables. For each condition engine was run for at least 3 min. The tests were replicated three times each, to confirm repeatability. A simple air-NG mixing device as shown in Fig. 2 was designed and fabricated and used to mix NG with inlet air during the suction stroke.

The intermediate values for the substitution ratio were used to evaluate performance and emissions of the dual fuel combustion. The diesel fuel rate to natural gas substitution equation used was:

$\mathrm{SR}_{\mathrm{D} / \mathrm{NG}}=\left[1-\left(\frac{\dot{\mathrm{m}}_{\mathrm{DF}}}{\dot{\mathrm{m}}_{\mathrm{OD}}}\right)\right]$

Where $m_{\mathrm{DF}}$ represents the diesel mass flow rate in dual fuel operation, and $\dot{\mathrm{m}}_{\mathrm{OD}}$ is the diesel fuel flow rate in original running. $\mathrm{SR}_{\mathrm{D} / \mathrm{NG}} \square \square$ represents the original diesel operation and $\mathrm{SR}_{\mathrm{D} / \mathrm{NG}} \square \square$ stands for dual fuel operation. The actual fuel/air ratio defined as:

Actual fuel/air ratio $=\mathrm{m}_{\text {fuel }} / \mathrm{m}_{\text {air }}=\left(\mathrm{m}_{\text {diesel }}+\mathrm{m}_{\mathrm{NG}}\right) / \mathrm{m}_{\text {air }}$

The stoichiometric fuel/ air ratio can be calculated by defining the fuel constituents. Then, equivalence ratio can be defined as [16]:

$\varnothing=\frac{\frac{[\mathrm{D}]}{[\text { air }]-\frac{[\mathrm{NG}]}{([\mathrm{NG}] /[\text { air }])_{\text {st }}}}}{\left(\frac{[\mathrm{D}]}{[\text { air }]}\right)_{\text {st }}}$

In dual fuel operation conditions, the brake specific fuel consumption (BSFC) can be derived from the fuel mass flow rates per unit power output. In order to manifest the effect of the difference between the lower heating values of both fuels a correction must be made:

$\mathrm{BSFC}=\left(\frac{\dot{\mathrm{m}}_{\mathrm{D}}+\left(\frac{\mathrm{LHV}_{\mathrm{NG}}}{\mathrm{LHV}_{\mathrm{D}}}\right) \dot{\mathrm{m}}_{\mathrm{NG}}}{1000 . \mathrm{BP}}\right)$

Where $\mathrm{LHV}_{\mathrm{NG}}$ and $\mathrm{LHV}_{\mathrm{D}}$ are the lower heating values of NG and diesel and BP is the output brake power. Engine performance parameters were calculated by the following equations [17]:

Brake power

$\mathrm{bp}=\frac{2 \pi * \mathrm{~N} * \mathrm{~T}}{60 * 1000} \quad \mathrm{~kW}$

Brake mean effective pressure 
bmep $=\mathrm{bp} \times \frac{2 * 60}{\mathrm{~V}_{\mathrm{sn}} * \mathrm{~N}} \mathrm{kN} / \mathrm{m}^{2}$

Air mass flow rate

$\dot{\mathrm{m}}_{\mathrm{a}, \mathrm{act} .}=\frac{12 \sqrt{\mathrm{h}_{\mathrm{o}} * 0.85}}{3600} \times \rho_{\mathrm{air}} \frac{\mathrm{kg}}{\mathrm{sec}}$

$\dot{\mathrm{m}}_{\mathrm{a}_{\text {theo }} .}=\mathrm{V}_{\mathrm{s} . \mathrm{n}} \times \frac{\mathrm{N}}{60 * 2} \times \rho_{\text {air }} \frac{\mathrm{kg}}{\mathrm{sec}}$

(8)

Brake thermal efficiency

$\eta_{\text {bth. }}=\frac{\mathrm{bp}}{\mathrm{Q}_{\mathrm{t}}} \times 100 \quad \%$

\section{Results And Discussion}

In the present work, engine performance and emissions were studied to introduce the effect of some engine operation variables (equivalence ratio, engine speed, and injection timing). In each case one of the mentioned variables was being changed while the others remained constant. For example, when equivalence ratio was studied, engine speed at $1500 \mathrm{rpm}$ with optimum injection timing was used, to evaluate engine performance parameters. $\mathrm{CO}, \mathrm{CO}_{2}$, unburned hydrocarbons (UBHC) and $\mathrm{NOx}$ were measured for each point in the same time.

\subsection{The effect of equivalence ratio}

Fig. 3 represents NG addition effect on resulted brake power for a wide range of equivalence ratios. Brake power started at low values at very lean mixtures and increased to reach its maximum value around $\emptyset=0.5$. After this equivalence ratio it started to reduce. In the present study soot production in black colored exhaust gases was observed at equivalence ratio around $\varnothing=0.6$. So, the equivalence ratio was not extended after this ratio. NG addition reduced the resulted bp for all studied equivalence ratios, due to its low heating value compared to diesel fuel, and because of its low burning speed.

Fig. 4 provides the variation of brake specific fuel consumption as a function of equivalence ratio. At low equivalence ratios, BSFC for dual fuel operation is higher than that for original diesel operation. The dual fuel performance is poorer at all ratios except for the ratios near that gave the maximum output. BSFC increased when a higher proportion of natural gas is used.

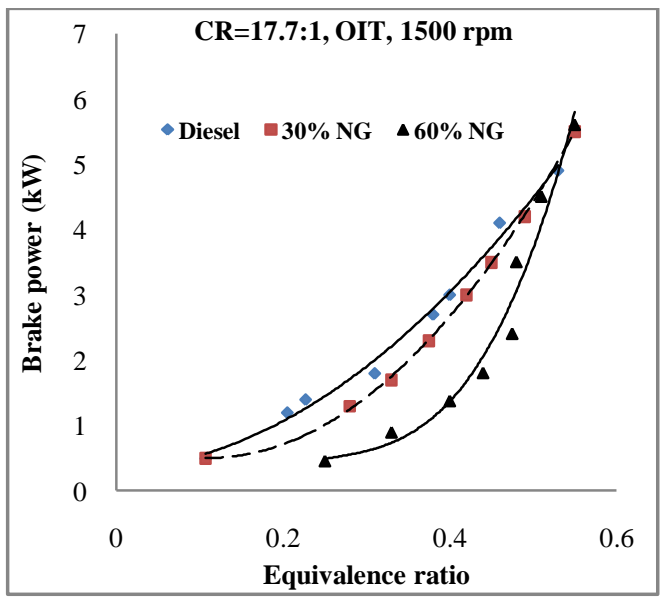

Fig. 3, NG addition effect on bp for tested equivalence ratio range

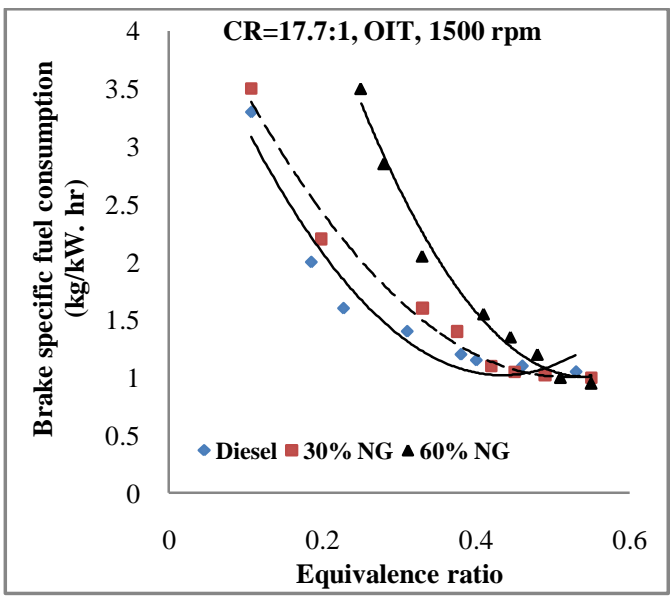

Fig. 4, NG addition effect on bsfe for tested equivalence ratio range

Exhaust gas temperatures reduced with increasing NG proportion in the duel fuel, as fig. 5 indicates. For the lean mixtures used, higher exhaust temperatures are produced when larger pilots and increasingly higher equivalence ratios are employed. Due to the increased delay periods and late combustion under dual fuel 
operation, higher temperatures at the end of the expansion stroke are encountered than the corresponding values for normal diesel operation. This can be referred to both the reflection of the increase in the proportion of gaseous fuel undergoing combustion and the associated increased energy release rates that continue further down the expansion stroke.

Indicated thermal efficiency reduced with adding NG to diesel fuel, as fig. 6 represents. Again, because of the above mentioned two reasons of NG negative specifications, and to reduce their effect increasing compression ratio can be used. In this work, the higher useful compression ratio (HUCR $=17.7)$ for the used diesel fuel was employed in all the tests.

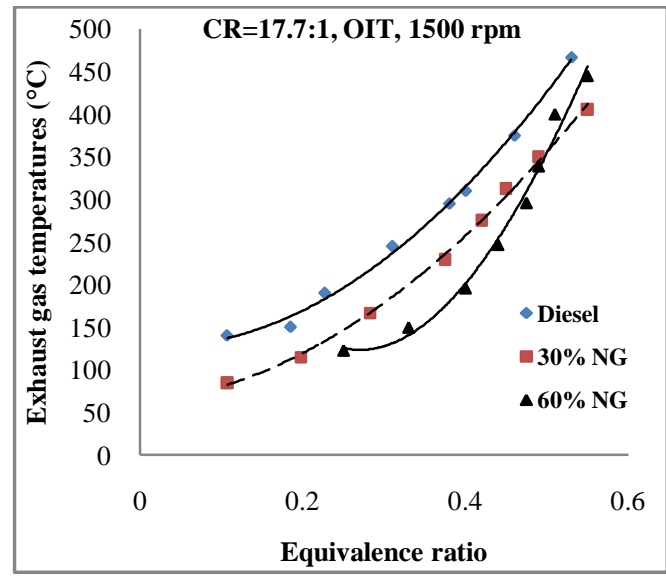

Fig. 5, NG addition effect on exhaust gas temperatures for tested equivalence ratio range

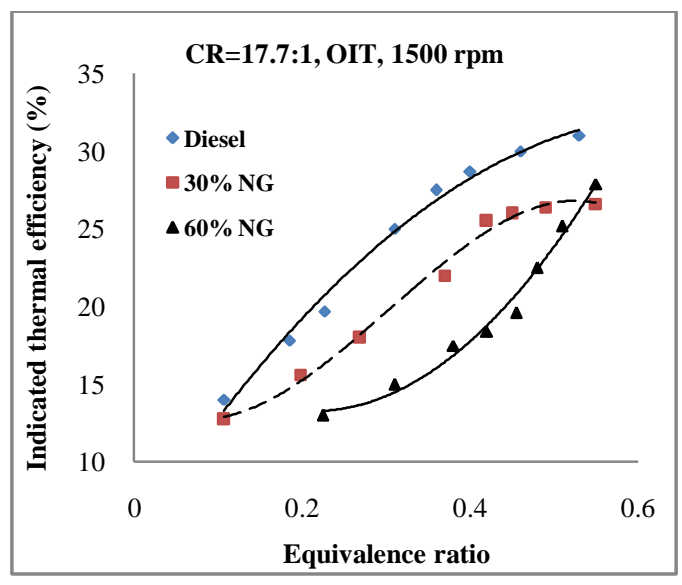

Fig. 6, NG addition effect on indicated thermal efficiency for tested equivalence ratio range

Volumetric efficiency reduced with increasing NG proportion in duel fuel, as fïg. 7 shows. NG was introduced in its gaseous phase, so this gas constrained its volume form air portion, reducing the volumetric efficiency.

In all the above figures, at $\mathrm{NG}=60 \%$ in the duel fuel the beginning equivalence ratio was at $\varnothing=0.25$, while for $30 \% \mathrm{NG}$ the beginning equivalence ratio was $\varnothing=0.11$. Increasing NG proportion in duel fuel accompanied with reducing pilot diesel fuel caused flame extinction at very low equivalence ratios. The reason for that can be referred to bad fuel preparation. In addition to the Ricardo engine combustion chamber design, where the mixtures ignited in pre-chamber and proceed to the main chamber. So, because it was very lean and bad mixing, the flame extinguished.

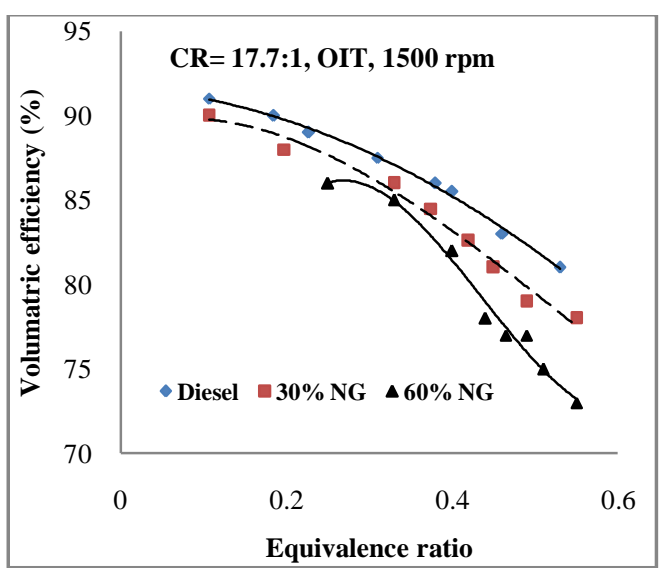

Fig. 7, NG addition effect on volumetric efficiency for tested equivalence ratio range

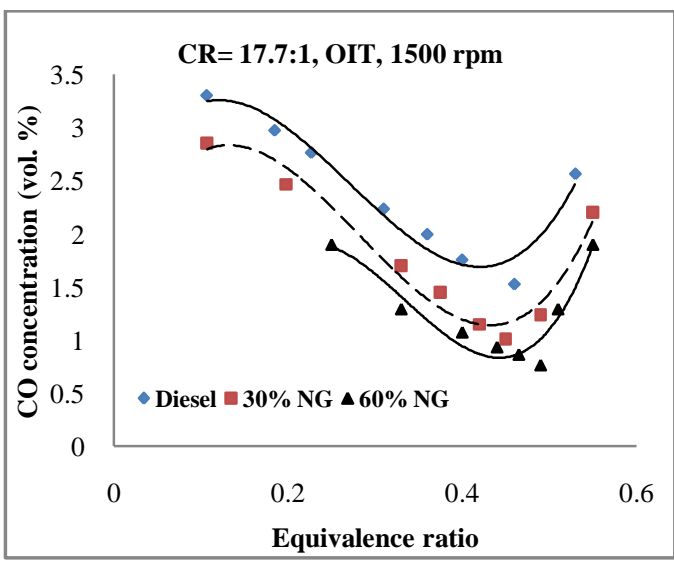

Fig. 8, NG addition effect on $\mathrm{CO}$ concentrations for tested equivalence ratio

Fig. 8 shows the variation of the CO concentration in exhaust gas with a wide range of equivalence ratios. Carbon monoxide is the primary intermediate product in the hydrocarbon fuel oxidation. For lean fuel-air mixtures; its presence in the exhaust is an indication that some of the oxidation reactions of the fuel could not be 
oxidized further to carbon dioxide. Most of the $\mathrm{CO}$ is produced from the partial oxidation of the gaseous fuel. These were due to the low charge temperature and relatively slow reaction rates of the gaseous fuel in the reacting zone. For higher gaseous fuel concentrations in the mixture, no partial oxidation was evident in dual fuel engine operation. The most of the $\mathrm{CO}$ was produced primarily from the pre-ignition reactions of the gaseous fuel within the unburnt zone. It appears that in the region of equivalence ratio around $\varnothing=0.5$, where the $\mathrm{CO}$ concentrations reaches its minimum value, propagated combustion reactions occur, even if the flame does not travel throughout the whole combustion chamber.

Fig. 9 represents $\mathrm{CO}_{2}$ concentrations against equivalence ratios. Due to the major component in natural gas, methane, that is believed to be the cleanest burning hydrocarbon. Methane produces less $\mathrm{CO}_{2}$ and more $\mathrm{H}_{2} \mathrm{O}$ than any other fossil fuels because of its high $\mathrm{H} / \mathrm{C}$ ratio. Another important aspect of methane combustion which contributed to its pristine image is the fact that its premixed flames with air do not produce soot; instead they are blown-out first because of flammability limit considerations.

NG addition reduced NOx concentrations, as fig. 10 represents, due to its low flame temperature, even at equivalence ratios produced high $\mathrm{CO}$ and UBHC concentrations. NOx reduction grows with adding more $\mathrm{NG}$, due to this character domination. NOx emissions in a dual fuel engine fuelled with NG were lower than the values observed during diesel operation. NOx emissions decrease mainly due to the lower combustion temperature and burning velocity of NG when compared to diesel operation as suggested by Ref. [18].

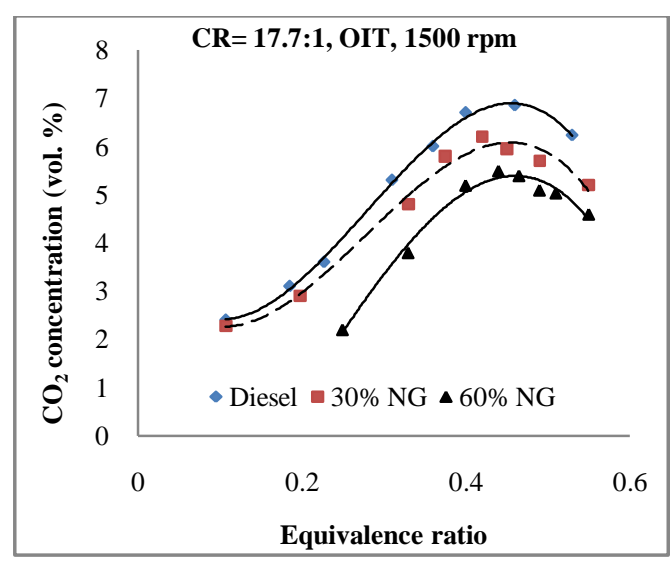

Fig. 9, $\mathrm{NG}$ addition effect on $\mathrm{CO}_{2}$ concentration $\mathrm{s}$ for tested equivalence ratio

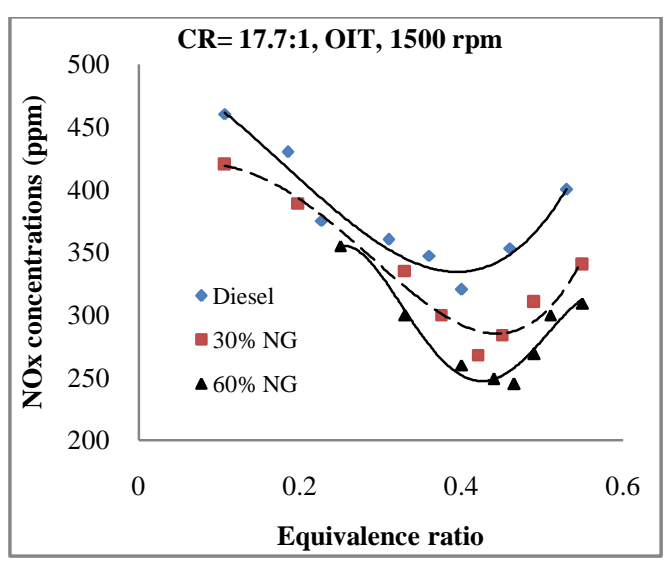

Fig. 10, NG addition effect on NOx concentrations for tested equivalence ratio

The variations of unburnt hydrocarbon concentration in the exhaust gases have a very similar trend to that observed for the $\mathrm{CO}$ concentrations. $\mathrm{HC}$ maximum values lie at slightly leaner mixtures than the $\mathrm{CO}$ maximum value (at $\varnothing=0.40$ ). Fig. 11 shows that a considerable fraction of the NG representing significant quantities of fuel can pass through the engine cylinder unreacted. When the engine runs at very lean mixtures, the poor atomization of the pilot with increased ignition delay, large cyclic variations, and low charge temperature, result in very low gaseous fuel utilization.

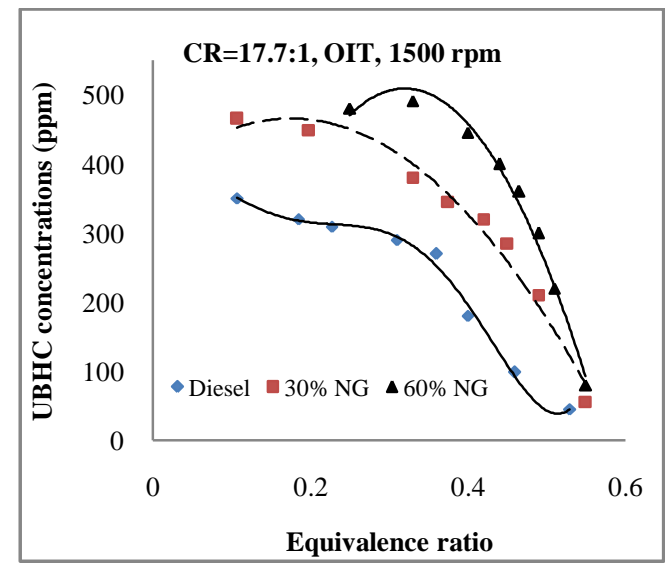

Fig. 11, NG addition effect on UBHC concentration $\mathrm{s}$ for tested equivalence ratio

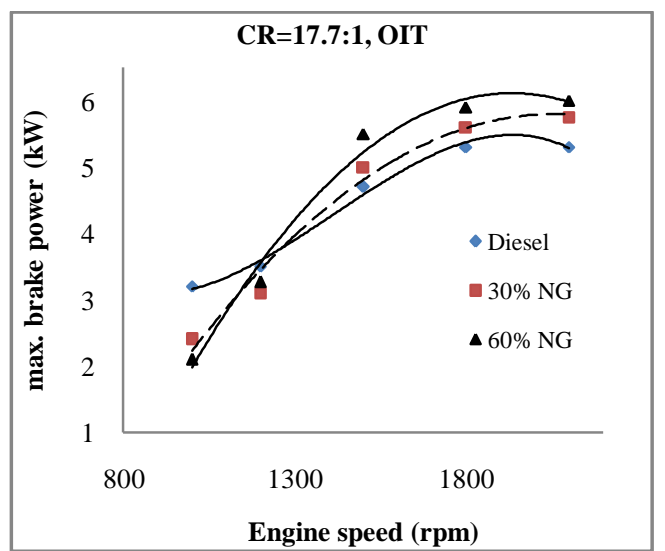

Fig. 12, NG addition effect on bp for tested engine speeds 
The UBHC, concentration increases initially with the increase in the NG concentration in air of the cylinder charge. For mixture strengths above $\varnothing=0.40$, the rapid decline of the unreacted methane percentage expectedly occurs as the effective lean flammability limit of the mixture is approached. The size of the pilot has a very significant influence on the level of the UBHC in the exhaust gases emissions as clarified by Ref. [10]. At very lean equivalence ratios operation, the utilization of the gaseous fuel is improved significantly with an increase in the quantity of the pilot fuel due to the increased rates of combustion.

\subsection{The effect of engine speed}

Brake power improved with increasing engine speed, and dual fuel represented higher bp at medium speeds (1400-2100 rpm) compared to diesel operation. Increasing engine speed increased turbulence inside combustion chamber, which increase air-fuel mixing, as a result, produced bp grow better, as fig. 12 represents.

Brake specific fuel consumption (bsfc) increased with increasing engine speed for diesel operation while it reduced with dual fuel operation, as the fig. 13 shows. Increasing engine speed improves duel fuel combustion and gives higher brake power, in the other hand reduces bsfc. Increasing engine speeds needs more diesel fuel to be injected, causes bsfc of diesel operation to increase.

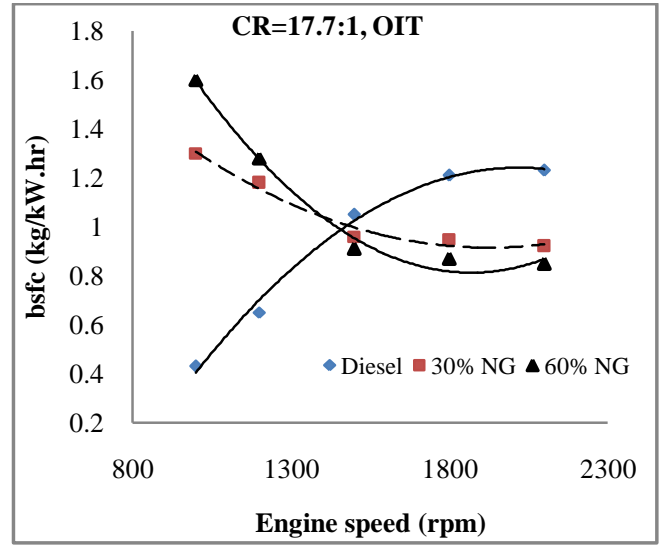

Fig. 13, NG addition effect on bsfc for tested engine speeds

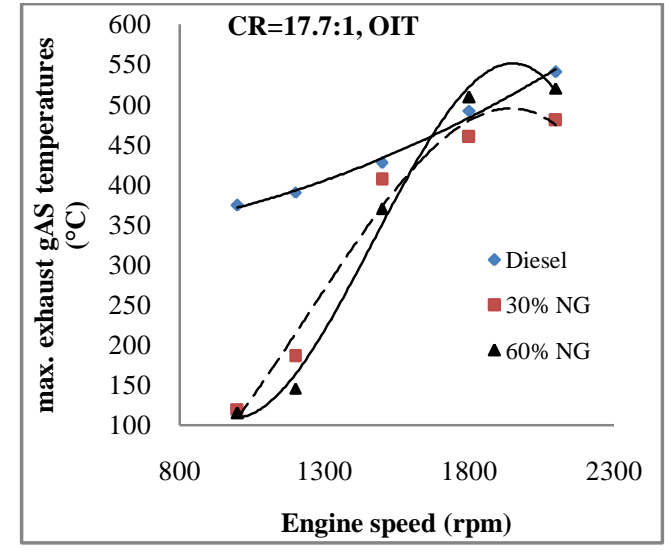

Fig. 14, NG addition effect on maximum exhaust gas temperatures for tested engine speeds

Fig. 14 represents the relation between engine speed and the maximum exhaust gas temperatures. For diesel fuel, these temperatures increased with about $37.5 \%$ for tested engine speeds, for $30 \%$ NG addition the increment was $275 \%$, and for $60 \%$ NG addition the increment was $363 \%$. Diesel fuel shows stability in its operation, so the increment in its exhaust temperature was acceptable. Adding NG in duel fuel operation improves the combustion with increasing engine speed, giving higher bp and less bsfc, in the other hand exhaust temperatures increased as a result to this improvement.

Fuel mixing improved with increasing engine speed, so $\mathrm{CO}$ concentrations reduced due to combustion improvements. Observing fig. 15, it is confirmed that $\mathrm{CO}$ emissions are consistent with the results for hydrocarbons. Under dual fuel operation, $\mathrm{CO}$ emissions are considerably higher than diesel operation. For the evaluated loads, increases in NG substitution correlate with increased $\mathrm{CO}$ emissions. However, such concentrations were lower under high loads used in these tests. Increase in engine speed seems to have a significant effect on carbon monoxide concentrations as observed for both cases. The reduction in $\mathrm{CO}$ concentrations was about $15 \%$ and $14.5 \%$ at $30 \%$ and $60 \%$ NG addition respectively, compared to neat diesel fuel.

The emission of unburdened hydrocarbons (UBHC) as a function of various engine speeds is illustrated in fig. 16. Unburnt hydrocarbons are the result of incomplete combustion of hydrocarbon fuel. Unburnt hydrocarbon concentrations in a diesel engine exhaust under normal conditions range from approximately 315 to $330 \mathrm{ppm}$.

As indicated in fig. 15, UBHC emissions under dual fuel operation mode are higher than that emitted by diesel operation. These results are fitted with the BSFC observed in fig. 4 and explained it. At low speeds, $\mathrm{HC}$ emissions raised rapidly. Under these conditions, the NG-air mixture is very lean that complicates flame propagation throughout the combustion chamber from the pilot ignition. For a constant substitution ratio (as in the recent study) with an increase in engine speed, there is a convenient decrease in HC concentrations. This decrement indicates an increase in partial reactions or better flame propagation. Lower values of $\mathrm{HC}$ concentrations were exhausted for speeds above $1800 \mathrm{rpm}$, under dual fuel operation. When dual fuel engine 
runs at higher than $2000 \mathrm{rpm}$, there is a little increment in $\mathrm{HC}$ emissions. This increment is believed to be caused by the reduced time available for oxidation reactions. In this work, the injected diesel was done at optimum injection timing, so it was changed with changing engine speed.

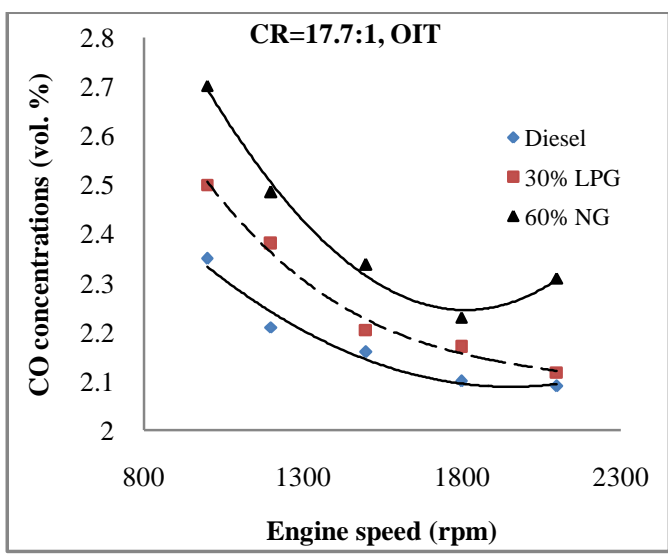

Fig. 15, NG addition effect on $\mathrm{CO}$ concentrations for tested engine speeds

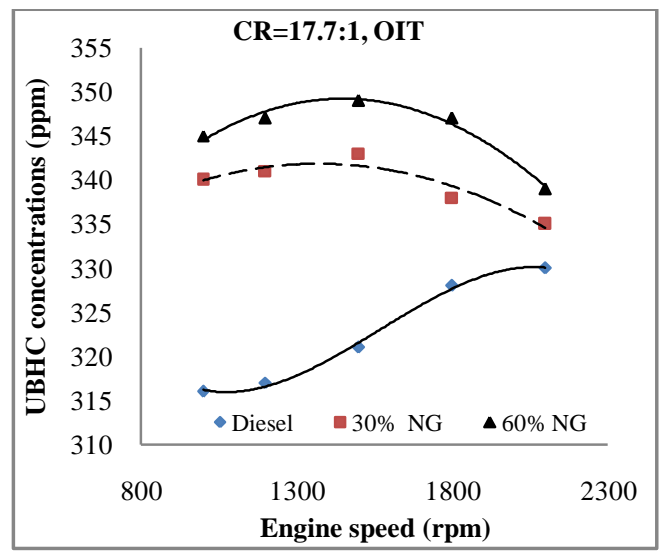

Fig. 16, NG addition effect on UBHC concentrations for tested engine speeds

The results presented in fig. 17 show the variation of nitrogen oxide concentrations for different engine speeds from 1000 to $2250 \mathrm{rpm}$. NOx concentrations in diesel engine exhaust are typically between 960 and 1260 ppm. As fig. 17 shows, NOx emissions are strongly dependent on the engine speed and the presence of natural gas in the charge mixture. For the tested engine speed range, NOx emissions were reduced when NG/diesel dual fuel were used in comparison with neat diesel fuel. Lower NOx emissions in dual fuel operation can be referred to the longer ignition delay of the pilot fuel than for the original diesel. Combustion temperature could be reduced by increasing the ignition delay period. Also, the presence of gaseous fuel replaces part of the intake air causing a reduction in the charge oxygen content could cause lower NOx.

\subsection{The effect of injection timing}

Optimum injection timing was used as a technique to achieve the previous figures, but this variable affected by NG addition, and as a result, it influences on engine performance and emissions were studied. Fig. 18 represents the resulted bmep for a wide range of injection timing, for the three tested fuels, at specific equivalence ratio, which was chosen as that gave the maximum bp.

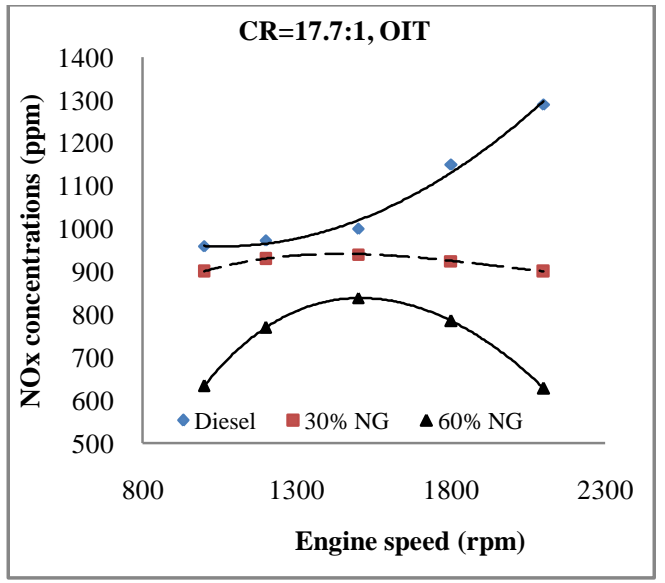

Fig. 17, NG addition effect on NOx concentrations for tested engine speeds

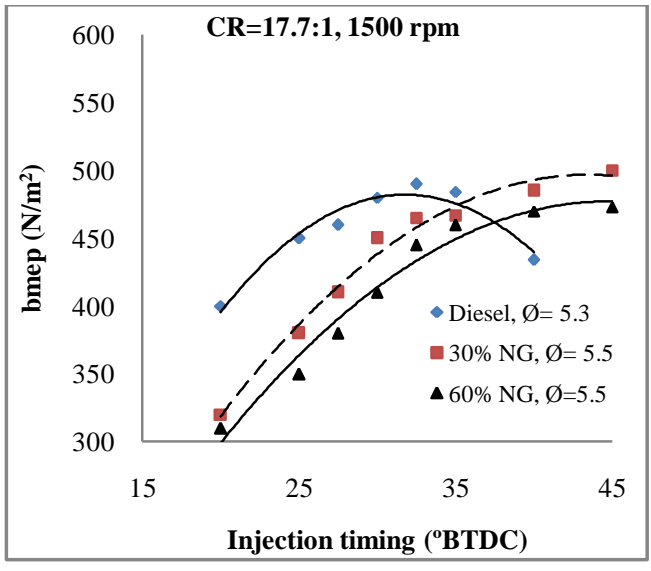

Fig. 18, NG addition effect on bmep for tested injection timing range of specific equivalence ratio

Injection timing variation gives indications on the available time for the fuel preparation. Optimum injection timing depends on fuel delay period, from the figure, it is obvious that adding NG increases delay period, and the optimum injection timing must be advanced from 10 to $15^{\circ} \mathrm{CA}$. Working at OIT resulted in the 
maximum bmep, while moving away from it reduced bmep value highly. Due to availability of electronic controls, engine can be operated at OIT easy these days.

BSFC reduces when the engine operates at OIT, and increases highly when injection timing advances or retards. As fig. 19 shows, the high increment in bsfc prevented the study of the engine operation when it is being retarded lower than $20^{\circ} \mathrm{BTDC}$, as well as advancing the injection timing more than $45^{\circ} \mathrm{BTDC}$.

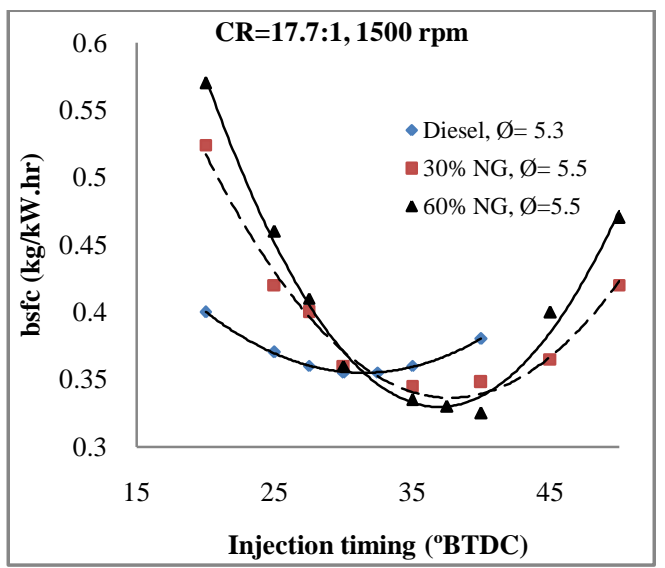

Fig. 19, NG addition effect on bsfc for tested injection timing range of specific equivalence ratio

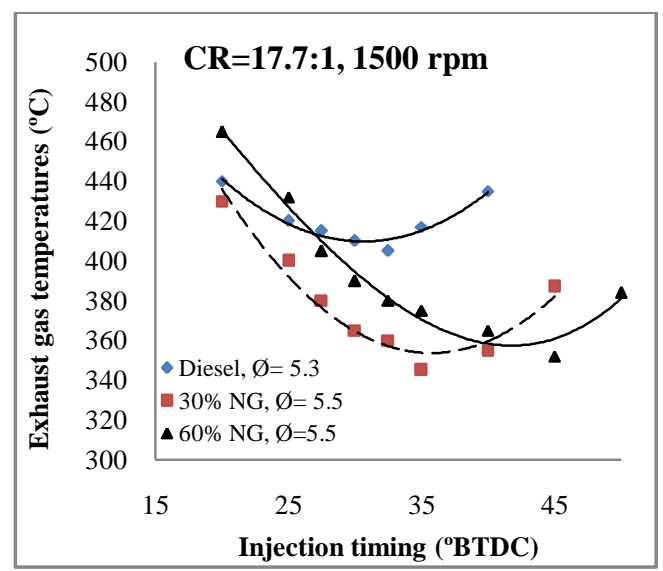

Fig. 20, NG addition effect on exhaust gas temperatures for tested injection timing range for specific equivalence ratio

Retarding injection timing increases exhaust gas temperatures, as fig. 20 indicates. A part of the fuel burnt after the piston reaches top dead centre. Continuing burning in the power stroke caused exhaust gases to run out with higher temperatures. Advancing injection timing in the other hand increases the delay period giving high combustion temperatures, in return higher exhaust gases.

Optimum injection timing (OIT) gave the minimum $\mathrm{CO}$ concentrations, as fig. 21 illustrates. Advancing or retarding injection timing increased these concentrations. Retarding injection timing reduces the available time for fuel to burn completely. Advancing injection timing increases heat inside combustion chamber, as a result, it increases the dissociation reactions from $\mathrm{CO}_{2}$ to $\mathrm{CO}$.

UBHC concentrations behave as $\mathrm{CO}$, as fig. 22 represents. Retarding injection timing reduces the available time for the fuel to complete burning. In the other hand, advancing injection timing gives little time for gaseous fuel to reach combustion chamber wall and inserts into the piston crevice. So, as the figure indicates the resulted UBHC from this procedure less than that resulted from retarding injection timing.

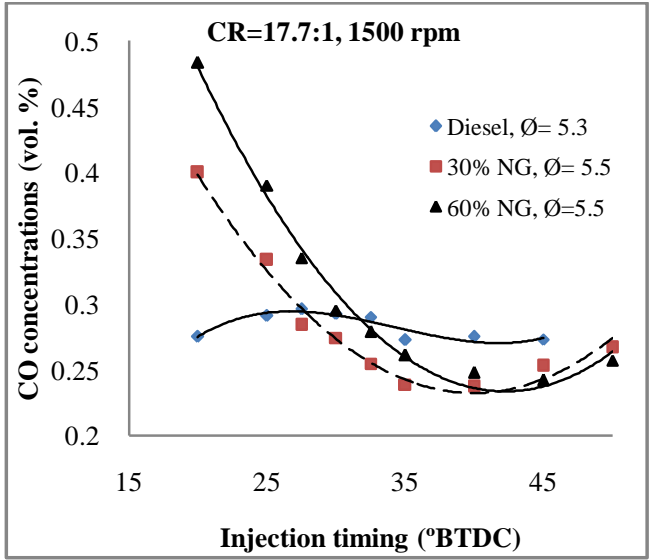

Fig. 21, NG addition effect on CO concentrations for tested injection timing range for specific equivalence ratio

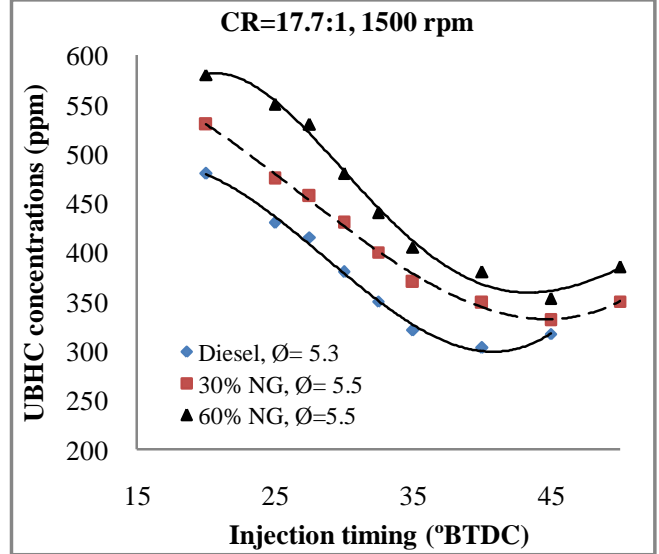

Fig. 22, NG addition effect on UBHC concentrations for tested injection timing range for specific equivalence ratio

The minimum $\mathrm{CO}_{2}$ concentrations were at OIT, as fig. 23 declares, due to the perfect burning of the fuel. The resulted $\mathrm{CO}_{2}$ reduced with additional $\mathrm{NG}$, due to increasing $\mathrm{H} / \mathrm{C}$ ratio accompanied with this addition. 
Retarding injection timing reduces NOx concentrations highly, due to a reduction in burning heat, as the fig. 24 clarifies. OIT and advanced timing gave higher NOx concentrations. NOx concentrations depend on two factors, available time, and high formation temperatures. At OIT the combustion chamber temperatures increase to its maximum values. As well as, advancing IT the available time for NOx will be enough to form high concentrations. It must be clear that studying the injection timing effect was done on specific equivalence ratio that gave the maximum bp.

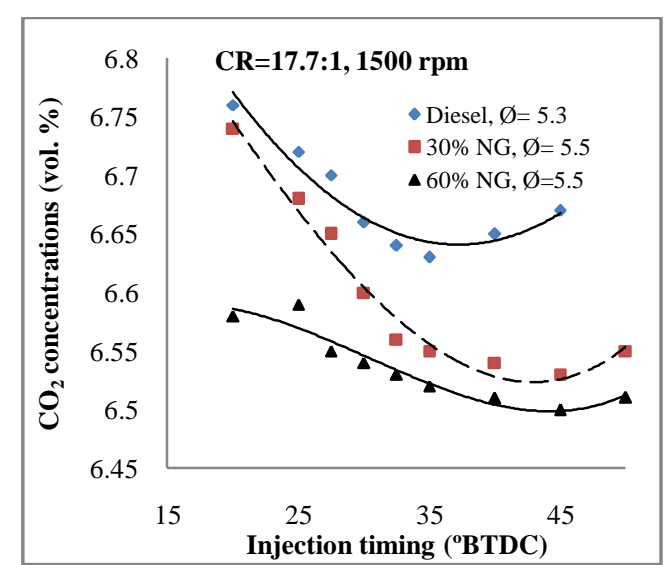

Fig. 23, $\mathrm{NG}$ addition effect on $\mathrm{CO}_{2}$ concentrations for tested injection timing range for specific equivalence ratio

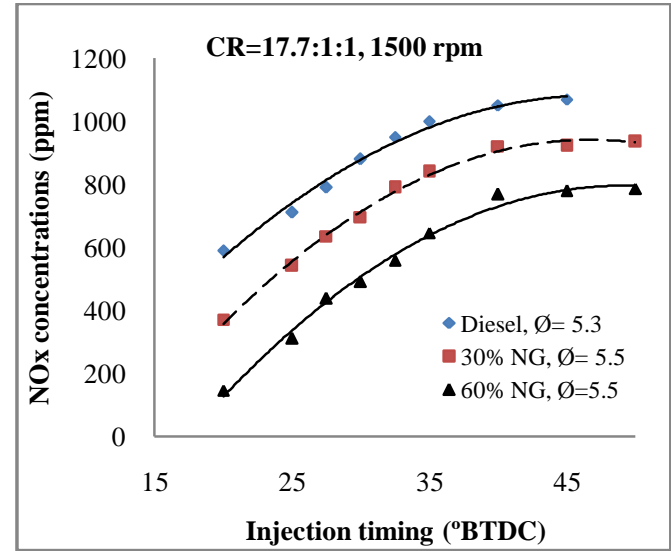

Fig. 24, NG addition effect on NOx concentrations for tested injection timing range for specific equivalence ratio

\section{Conclusions}

In this work, an experimental investigation conducted to identify the performance and emissions characteristics of natural gas/diesel dual fuel Ricardo engine; various new combustion phenomena were observed compared to original diesel engine. From the study carried out the following conclusions may be drawn:

- At very lean equivalence ratios and low loads, the brake specific fuel consumption under dual fuel conditions, is higher than original diesel operation for evaluated engine speeds. At higher equivalence ratios with higher loads and NG substitution, dual fuel engine performance is poorer. At light load, a part of the gaseous fuel was left to pass unburnt through the engine cylinder, probably due to the poor flame propagation. Lean operation with low loads resulted in poor fuel utilization and power output, and it reduced the efficiency.

- With very lean gaseous fuel-air ratios, the flames initiated from ignition centers of diesel pilot spray may fail to propagate throughout the whole combustion chamber. Various amounts of the gaseous fuel-air charge may be left unconverted.

- The ignition and combustion processes depended not only on the injection and ignition characteristics of the diesel pilot, but also depended strongly on the type and concentration of the gaseous fuel employed.

- $\quad$ The concentration of CO and UBHC peaked around mixture strength of an equivalence ratio of 0.4 to 0.5 . Any increase or decrease in the gaseous fuel concentration could reduce the presence of $\mathrm{CO}$ and unreacted $\mathrm{CH}$, in the exhaust gas.

- $\quad \mathrm{CO}$ and unburnt $\mathrm{CH}$ concentrations in the exhaust increased while NOx concentrations decreased.

- The increased HC and CO emissions found with NG addition at light load to the fact that the ignition delay is much longer during operation with NG. The admission of NG produced lower concentrations of NO, particularly at light loads, in comparison to diesel operation.

- NOx emissions in a dual fuel engine fuelled with natural gas were lower than the values observed during neat diesel operation of the engine. NOx emissions decrease mainly due to the lower combustion temperature and burning velocity when compared to diesel operation.

\section{References}

[1] M. T. Chaichan and A. M. Saleh A M, Practical investigation of performance of single cylinder compression ignition engine fueled with dual fuel, The Iraqi Journal for Mechanical and Material Engineering, 1399 (2),2013,198-211.

[2] M. L. Casako, Development of a diesel-gas mechanical dual fuel kit (In Portuguese), MSc. Thesis, Pontifical Catholic University of Rio de Janeiro, RJ, Brazil, 2005.

[3] J. Riffkin, Town gas as a fuel in the compression ignition engines, Gas Oil Power, 32 (35), 1937.

[4] G. A. Karim, W. Jones and R. R. Raine, An examination of the ignition delay period in dual fuel engines, SAE paper No. 892140, 1989. 
[5] G. A. Karim, An examination of some measures for improving the performance of gas fuelled diesel engine at light load, SAE paper No. $912366,1991$.

[6] S. K. Mahla, L. M. Das and M. K. G. Babu, Effect of EGR on performance and emission characteristics of natural gas fueled die sel engine, Jordan Journal of Mechanical and Industrial Engineering, 4 (4), 2010, 523 - 530.

[7] C. D. Gunea, Examination of the effects of pilot fuel quality on the performance of gas fueled diesel engines, MSc thesis, University of Calgary, Canada, 1997.

[8] J. C. Egúsquiza, S. L. Braga and C. V. M. Braga, Performance and gaseous emissions characteristics of a natural Gas/diesel dual fuel turbocharged and after cooled engine, J. of the Braz. Soc. of Mech. Sci. \& Eng. 31(2), 2009.

[9] Semin, A. Idris and R. Abu Bakar, An overview of compressed natural gas as an alternative fuel and Malaysian Scenario, European Journal of Scientific Research, 34(1), 2009, 6-15.

[10] L. Shenghua, Z. Longbao, W. Ziyan and R. Jiang, Combustion characteristics of compressed natural gas/diesel dual-fuel turbocharged compressed ignition engine, Proc. Instn. Mech. Engrs. - Part D: J. Automobile Engineering, 217, 2003, 833-838.

[11] R. G. Papagiannakis and D. T. Hountalas, Combustion and exhaust emissions characteristics of a dual fuel compression ignition engine operated with pilot diesel fuel and natural Gas, Energy Conversion and Management, 45, 2004, 2971 -2987.

[12] G. A. Karim, Combustion in gas fueled compression ignition engines of the dual fuel type, J. Eng. Gas Turb. Power, vol.125, 2003, $827-836$.

[13] R. H. Pereira, Experimental investigation and performance estimate of diesel engines burning natural gas, (In Portuguese), PhD thesis, Pontifical Catholic University of Rio de Janeiro, RJ, Brazil, 2006.

[14] T. C. Zannis, D. T. Hountalas, R. G. Papagiannakis and Y. A. Levendis, Effect of fuel chemical structure and properties on diesel engine performance and pollutant emissions: review of the results of four European research programs, SAE paper No. 2008-010838, 2008.

[15] R. Saidur, I. Jahirul, T. Z. Moutushi, H. Imtiaz and H. H. Masjuki, Performance investigations of a four cylinder diesel engine by partial substitution of diesel with natural gas, Proceeding to the international conference in recent advances in mechanical \& material engineering, 30-31 May, Kuala Lumpur, Malaysia, 2005, Paper No. 258.

[16] S. M. Abdul Haleem, Theoretical and experimental investigation of engine performance and emissions of a four strokes spark ignition engine operated with hydrogen blended gasoline, Ph D thesis, College of Engineering, Al-Mustansiriya University, Baghdad, Iraq, 2007.

[17] E. L. Keating E L, Applied combustion, 2nd edition, (Taylor \& Francis Group, LLC, 2007).

[18] S. Singh, The effect of fuel injection timing and pilot quantity on the pollutant emissions from a pilot-ignited natural gas engine, MSc thesis, The University of Alabama, USA, 2002.

\section{Nomenclature}

$\begin{array}{llll}\text { [air] } & \text { molar concentration of air } & \mathrm{N} & \text { engine speed (rpm) } \\ \text { bmep } & \text { brake mean effective pressure } & \mathrm{OIT} & \text { Optimum injection timing } \\ \text { bp } & \text { brake power } & \mathrm{T} & \text { engine torque (Nm) } \\ \text { bsfc } & \text { brake specific fuel consumption } & \mathrm{TDC} & \text { top dead centre } \\ \text { BTE } & \text { brake thermal efficiency } & \mathrm{m}_{\mathrm{a}, \text { act }} & \text { actual air flow rate } \\ \text { CA } & \text { crank angle } & \mathrm{V}_{\mathrm{s.n}} & \text { displacement volume } \\ {[\mathrm{D}]} & \text { Molar concentration of diesel fuel } & \mathrm{Q}_{\mathrm{t}} & \text { engine total heat } \\ \mathrm{HUCR} & \text { higher useful compression ratio } & \varnothing & \text { Equivalence ratio } \\ \text { LHV } & \text { lower heating value } & \rho_{\mathrm{f}} & \text { fuel density }\left(\mathrm{kg} / \mathrm{m}^{3}\right) \\ \text { [NG] } & \text { molar concentration of natural gas } & \mathrm{v}_{\mathrm{f}} & \text { fuel volume }\end{array}$

